\title{
South African guidelines on the determination of death
}

D Thomson, ${ }^{1}$ FCS (SA), MMed (Surg), Cert Crit Care; I Joubert ${ }^{2}$ FCA (SA); K De Vasconcellos, ${ }^{3}$ FCA (SA), MMedSc, Cert Crit Care;

F Paruk, ${ }^{4} \mathrm{PhD}$; S Mokogong, ${ }^{5} \mathrm{MB} \mathrm{ChB}$; R Mathivha, ${ }^{6}$ FCPaed (SA), Cert Crit Care, DBS (BM); M McCulloch, ${ }^{7}$ FCPaed (SA);

B Morrow, ${ }^{8} \mathrm{PhD}, \mathrm{BSc}$ (Physio), PG Dip (Health Research Ethics), PG Dip (Paed Palliative Med); D Baker, ${ }^{9} \mathrm{MB}$ ChB, FRCP (Lond);

B Rossouw, ${ }^{10}$ MMed (Paed), Cert Crit Care (Paed); N Mdladla, ${ }^{11}$ FCA (SA); G A Richards, ${ }^{12}$ PhD; N Welkovics, ${ }^{13}$ FCS (SA), Cert Crit Care;

B Levy, ${ }^{14} \mathrm{MB}$ ChB; I Coetzee, ${ }^{15}$ BCur (IetA), MCur (Crit Care), PGCHE, PhD, Dip Crit Care; M Spruyt, ${ }^{16}$ MMed (Chir) Crit Care;

N Ahmed, ${ }^{17}$ FCS (SA), MMed Surgery (SU), Cert Crit Care; D Gopalan, ${ }^{18}$ MB ChB, FCA (SA), Crit Care

${ }^{1}$ Division of Critical Care, Department of Surgery, University of Cape Town, Groote Schuur Hospital, Cape Town, South Africa

${ }^{2}$ Division of Critical Care, Department of Anaesthesia and Peri-operative Medicine, University of Cape Town and Groote Schuur Hospital,

Cape Town, South Africa

${ }^{3}$ Department of Critical Care, King Edward VIII Hospital, Durban, South Africa; Discipline of Anaesthesiology and Critical Care, School of Clinical Medicine, University of KwaZulu-Natal, Durban, South Africa

${ }^{4}$ Department of Critical Care, University of Pretoria, South Africa

${ }^{5}$ Department of Neurosurgery, University of Pretoria, South Africa

${ }^{6}$ Department of Critical Care, Faculty of Health Sciences, University of the Witwatersrand, Johannesburg, South Africa

${ }^{7}$ Paediatric Intensive Care Unit and Transplant Unit, Red Cross War Memorial Children's Hospital and Faculty of Health Sciences, University of Cape Town, South Africa

${ }^{8}$ Department of Paediatrics and Child Health, Faculty of Health Sciences, University of Cape Town, South Africa

${ }^{9}$ Department of Adult Critical Care, Livingstone Hospital and Faculty of Health Sciences, Walter Sisulu University, Port Elizabeth, South Africa

${ }^{10}$ Paediatric Intensive Care Unit, Red Cross War Memorial Children's Hospital and Faculty of Health Sciences, University of Cape Town, South Africa

${ }^{11}$ Dr George Mukhari Academic Hospital, Sefako Makgatho University, Johannesburg, South Africa

${ }^{12}$ Department of Critical Care, Faculty of Health Sciences, University of the Witwatersrand, Johannesburg, South Africa

${ }^{13}$ Netcare Unitas Hospital, Centurion, South Africa

${ }^{14}$ Netcare Rosebank Hospital, Johannesburg, South Africa

${ }^{15}$ Department of Nursing Science, University of Pretoria, South Africa

${ }^{16}$ Busamed Bram Fischer International Airport Hospital, Bloemfontein, South Africa

${ }^{17}$ Consolidated Critical Care Unit, Tygerberg Hospital, Department of Surgical Sciences, Department of Anaesthesiology and Critical Care, Faculty of Medicine and Health Sciences, Stellenbosch University, Cape Town

${ }^{18}$ Discipline of Anaesthesiology and Critical Care, School of Clinical Medicine, University of KwaZulu-Natal, Durban, South Africa

Corresponding author: D Thomson (David.Thomson@uct.ac.za)

Death is a medical occurrence that has social, legal, religious and cultural consequences requiring common clinical standards for its diagnosis and legal regulation. This document compiled by the Critical Care Society of Southern Africa outlines the core standards for determination of death in the hospital context. It aligns with the latest evidence-based research and international guidelines and is applicable to the South African context and legal system. The aim is to provide clear medical standards for healthcare providers to follow in the determination of death, thereby promoting safe practices and high-quality care through the use of uniform standards. Adherence to such guidelines will provide assurance to medical staff, patients, their families and the South African public that the determination of death is always undertaken with diligence, integrity, respect and compassion, and is in accordance with accepted medical standards and latest scientific evidence.

The consensus guidelines were compiled using the AGREE II checklist with an 18-member expert panel participating in a three-round modified Delphi process. Checklists and advice sheets were created to assist with application of these guidelines in the clinical environment (https://criticalcare.org.za/resource/death-determination-checklists/).

Key points

- Brain death and circulatory death are the accepted terms for defining death in the hospital context.

- Death determination is a clinical diagnosis which can be made with complete certainty provided that all preconditions are met.

- The determination of death in children is held to the same standard as in adults but cannot be diagnosed in children $<36$ weeks' corrected gestation.

- Brain-death testing while on extra-corporeal membrane oxygenation is outlined.

- Recommendations are given on handling family requests for accommodation and on consideration of the potential for organ donation.

- The use of a checklist combined with a rigorous testing process, comprehensive documentation and adequate counselling of the family are core tenets of death determination. This is a standard of practice to which all clinicians should adhere in end-of-life care.

S Afr Med J 2021;111(4b):367-380. https://doi.org/10.7196/SAMJ.2021.v111i4b.15200 | South Afr J Crit Care 2021;37(1b):41-54. https://doi.org/10.7196/SAJCC.2021v37i1b.466

Death is a medical occurrence that has social, legal, religious and cultural consequences requiring common clinical standards for its diagnosis and legal regulation. ${ }^{[1]}$ There is no documented case of a person who fulfils the preconditions and criteria for brain death ever subsequently developing any return of brain function. ${ }^{[2,3]}$
Clear medical standards for death certification augment the quality and rigor of death determination. ${ }^{[4-6]}$ Currently there are no clinical guidelines on death determination in South Africa (SA), with clinicians using available international guidelines, which vary markedly and are not always applicable to the SA context. ${ }^{[7-10]}$ The World Federation 
of Societies of Intensive and Critical Care Medicine (WFSICCM) recently published a document, based on current literature, aiming to standardise terminology and establish minimum testing standards across the world. ${ }^{[5]}$ In order to be applicable over a range of legal jurisdictions, some sections of this document are necessarily broad, making application to the local context challenging. There is therefore a need to align the WFSICCM document with the SA context and legal system, and to provide clear guidance to SA practitioners and the public.

The aims of this document are to provide guidelines for healthcare providers for the testing process, and to answer key questions that commonly arise when medical professionals are called upon to determine death in SA. The objectives are to:

- provide clear medical standards for healthcare providers in the determination of death, in order to promote safe practice and avoid diagnostic errors in the determination of death

- provide assurance to patients, their families and the SA public that determination of death is undertaken with diligence, integrity, respect and compassion and in accordance with accepted medical standards and societal expectations

- create a checklist for brain death and circulatory death determination.

\section{Methods}

An expert panel was constituted and reviewed current evidence and compiled consensus-based recommendations for the minimum standards required for death determination, applicable in the SA context, using a modified Delphi process. All statements in this guideline are considered strong recommendations. In cases where evidence is less strong, the term 'suggested' is used to indicate a lower level of evidence. Statements are intentionally similar to international documents in the interests of commonality of approach. Recommendations are aligned with the best interests of patients and their families.

\section{Panel recruitment}

Expert panel members were recruited through the Critical Care Society of Southern Africa (CCSSA) as experts in the field of death determination and end-of-life care representing a broad range of disciplines within critical care (neurosurgery, paediatrics, obstetrics and gynaecology, surgery, anaesthesiology, nursing, ethics). Informed consent was given by the expert panel with acknowledgement that they would be identifiable in the publication (Appendix 1 - 3: http:// samj.org.za/public/sup/15200-1.pdf). The study methodology was approved by the University of Cape Town Human Research Ethics Committee (HREC 476/2019).

\section{Delphi process}

A literature search of Pubmed, Web of Science, SCOPUS and the grey literature was conducted by the steering committee of the expert panel and a professional librarian to identify national and professional society guidelines in death determination, and their supporting evidence, for review (http://samj.org.za/public/sup/15200-2.pdf). A modified Delphi approach was used with adherence to the Appraisal of Guidelines for Research and Evaluation (AGREE II) instrument to compile the guidelines. ${ }^{[11]}$

Key questions related to current principles and practice regarding death certification were drafted by the meeting steering committee. During three rounds of a modified Delphi process ${ }^{[12]}$ using Surveymonkey (SVMK Inc., USA), a web-based application, the expert panel progressively modified, deleted or added questions and components. Participants were asked to rate agreement with each component between 1 and 9 on a Likert scale, with 1 - 3 being 'not important', 3 - 6 being 'important but not critical' and 7 - 9 being 'critically important', or state if they were unable to comment. This scale is recommended by the Grading of Recommendations Assessment, Development and Evaluation working group. ${ }^{[1,13]}$ Participants were invited to suggest additional questions for consideration for the round table in each round using free-text responses. Although five to 10 experts are considered adequate for content validation, we used 18 to ensure a broadly representative group. ${ }^{[14]}$

Precise terminology was reviewed and finalised in order to improve clarity in death determination discussions and debate. We defined consensus for the Delphi a priori based on guidance in The COMET Handbook. ${ }^{[15]}$ For inclusion in the consensus outcome statement (COS), outcomes required at least $70 \%$ of participants in each stakeholder group to score the outcome as critically important and $<15 \%$ to score the outcome as not important. Outcomes excluded from the COS required at least $70 \%$ of participants in each stakeholder group to score the outcome as not important and $<15 \%$ to score the outcome as 'critical'. If outcomes did not meet either criterion, they were presented at the round-table for discussion. The expert panel members summarised the responses and the available evidence and formulated draft recommendations that were presented and discussed at a faceto-face round table meeting prior to the CCSSA national conference in Cape Town, SA, in 2019. The results were presented at a plenary meeting of the conference.

All questions and feedback from this meeting were then reviewed with the steering committee. The combined consensus statement and proposed guideline were circulated to all society members for comment over three months. All expert panel members approved the final document for publication. The guidelines were then submitted for external review and endorsement by other South African professional medical societies (Table 1).

\section{Updating of the guidelines}

A review period of five years was set after publication of this document, the review to be undertaken by the guideline development group of the CCSSA, unless an earlier revision is mandated by emerging high-quality medical evidence or legislative changes.

\section{South African guidelines on the determination of death}

\section{General statements}

Death is the clinical point of irreversible loss of the capacity for consciousness and the irreversible loss of the capacity to breathe. ${ }^{[16]}$

Death is determined by either neurological or circulatory criteria and must be made in accordance with accepted medical standards. ${ }^{[1]}$

Table 1. List of endorsing societies

Trauma Society of Southern Africa

The Association of Surgeons of South Africa

Radiology Society of South Africa

Southern African Transplantation Society

Islamic Medical Association

South African Medical Association

Resuscitation Council of South Africa

South African Thoracic Society

Colleges of Medicine of South Africa - Committee of Critical Care

Neurological Association of South Africa

Society of Neurosurgeons of South Africa

South African Paediatric Association (Affirmation of Value) 
A correctly performed clinical examination can determine the point of death with complete certainty. It is not necessary to wait for pathognomonic signs of death (hypostasis, rigor mortis, decay) to be present in the healthcare setting. ${ }^{[16,17]}$

In cases where there are confounders affecting the clinical examination, testing should be deferred until such confounders are resolved or ancillary testing confirms the diagnosis of death. ${ }^{[17]}$

\section{Definitions}

Ancillary test: an additional test that can assist with the clinical diagnosis of brain death. ${ }^{[18]}$

Accommodation: a period of somatic support to allow for family to process the diagnosis of death.

Brain death/death by neurological criteria: the preferred term when death is determined on neurological grounds. (This is in preference to the term brain-stem death and is in alignment with the latest guidelines. $)^{[5]}$

Circulatory death/death by circulatory criteria: the preferred term when death is determined on circulatory grounds. (This is in preference to terms such as cardiac or cardiorespiratory death and is in alignment with the latest guidelines. ${ }^{[1]}$

Coma: the absence of wakefulness, awareness and the capacity for sensory perception and responsiveness to the external environment. ${ }^{[1]}$

Confounder: a situation during which a diagnostic test may be unreliable. Repeat testing when the confounder is no longer present, or ancillary testing, is required to diagnose death in these settings.

Somatic support: management to support the body and organs, excluding the brain, after brain death has been confirmed.

\section{Brain death}

\subsection{Preconditions for brain death testing}

There must be an established aetiology compatible with complete and irreversible loss of all brain function prior to commencement of the determination of brain death.

Preconditions for brain-death testing to be valid are:

- a minimum temperature of $36^{\circ} \mathrm{C}^{[2,5]}$

- a systolic blood pressure (BP) $\geq 100 \mathrm{mmHg}$ or a mean arterial pressure (MAP) $\geq 60 \mathrm{mmHg}$ (or age-appropriate haemodynamic targets in the paediatric population)

- exclusion of the influence of central nervous system (CNS) depressing drugs. This is done by at least one of the following:

- allowing five elimination half-lives of the drug to pass before making an evaluation of brain death (taking into consideration the dose and the elimination half-life, which may be influenced by age, organ dysfunction or prior hypothermia) ${ }^{[5]}$

- administering an appropriate drug antagonist

- measuring drug levels ${ }^{[5]}$

- performing ancillary testing in addition to a complete clinical examination if there is concern about prolonged or unknown drug elimination

- intact neuromuscular function

- If doubt exists regarding the effects of pharmacological paralysis, a train-of-four nerve stimulator can be used. A normal response to stimulation should be observed. ${ }^{[3]}$

- correction of severe metabolic, acid-base and endocrine derangements that could affect the examination

- If these derangements cannot be corrected and are judged to be potentially contributing to the loss of brain function, ancillary testing must be used after a clinical examination of brain death has been completed.

\subsubsection{Additional remarks: Preconditioning ${ }^{[5]}$}

Neuroimaging is recommended when available to assist with establishing an aetiology and confirming brain injury.

Neuroimaging is not required for the diagnosis of brain death where an obvious cause is known.

Drug levels should not exceed the therapeutic range and, if within a therapeutic range, not be associated with an altered level of consciousness.

Barbiturates have long and variable elimination half-lives, so blood levels should be measured and documented to be below that of clinically significant effects $(<10 \mathrm{mg} / \mathrm{L})$ or alternatively ancillary testing should be used to diagnose brain death.

If there is concern about severe alcohol intoxication being the primary cause of coma, the blood alcohol level should be shown to be $<80 \mathrm{mg} / \mathrm{dL}$.

Consensus was not achieved on a standardised observation period prior to brain-death testing. The appropriate observation period was felt to be specific to each individual case. However:

- in cases of anoxic brain injury, this observation period should be 24 hours

- in cases where therapeutic hypothermia was used, there should be a 24-hour period of normothermia prior to an examination for brain death

- in paediatrics, a cautious approach is advised, given the frequent presence of confounders in this group.

It must be possible to adequately examine the brain-stem reflexes. It must be possible to examine at least one eye and one ear and safely perform apnoea testing. ${ }^{[3,5]}$

Apnoea testing may be precluded by severe hypoxic respiratory failure or a high cervical cord injury, in which case ancillary testing can be used after confirming that brain-stem reflexes are absent. ${ }^{[3,5]}$

While trying to provide broad guidance on the magnitude of metabolic and endocrine disorders which are likely to influence the testing of brainstem reflexes, it is essential to bear in mind that the most important factor is the establishment of an unequivocal cause for the individual's coma. $^{[17]}$

It is recognised that circulatory, metabolic and endocrine disturbances (e.g. hypotension, hypernatraemia, diabetes insipidus) are likely accompaniments of death as a result of cessation of brain-stem function. It is important to emphasise that these may be the effect rather than the cause of cessation of brain function and do not preclude the diagnosis of death by neurological testing. ${ }^{[17]}$

It is recognised that: ${ }^{[17]}$

- Sodium can cause unresponsiveness at levels $<115$ or $>160 \mathrm{mmol} / \mathrm{L}$.

- Serum potassium levels can cause flaccid paralysis below $1 \mathrm{mmol} / \mathrm{L}$. Therefore, we recommend a level $>3 \mathrm{mmol} / \mathrm{L}$ be confirmed.

- Profound elevation or lowering of phosphate or magnesium can be associated with severe neuromuscular weakness at levels $<0.5$ or $>3.0$ $\mathrm{mmol} / \mathrm{L}$ and may need to be corrected.

- Hyperglycaemia in diabetic ketoacidosis or hyperosmolar non-ketotic coma may cause a state of unresponsiveness which mimics irreversible cessation of brain-stem function, but this state is extremely unlikely with blood glucose levels $<20 \mathrm{mmol} / \mathrm{L}$.

- Severe hypoglycaemia is associated with coma or stupor and testing of brain-stem reflexes should not be undertaken if the glucose level is $<4 \mathrm{mmol} / \mathrm{L}$. As blood glucose concentrations change rapidly in critically ill patients, a blood glucose measurement should always be made immediately prior to the testing of brain-stem reflexes. 
The following endocrine conditions are extremely rare and unlikely to co-exist in the presence of known primary pathologies. If there is any clinical reason to expect these disturbances, then it is obligatory to ensure appropriate hormonal assays are undertaken.

- Myxoedema may cause a deep unresponsive coma.

- An Addisonian crisis may be associated with severe neuromuscular weakness, causing an acute ascending paralysis or encephalopathy proceeding to coma.

\subsection{Braindeath testing ${ }^{[3,5,17]}$}

The testing process comprises assessment for:

1. coma

2. absence of brain-stem reflexes

3. inability to breathe.

A detailed explanation of the testing process is outlined (Table 2).

\section{Table 2. Clinical testing for brain death - coma, brain stem reflexes, apnoea test}

\begin{tabular}{ll}
\hline Clinical testing for & Test and interpretation \\
\hline 1. Coma & Test: Assess both centrally and peripherally. Apply \\
deep pressure to all of the following: \\
- the condyles at the level of the temporomandibular \\
joints \\
- the supra-orbital notch bilaterally \\
- the sternal notch \\
Interpretation: Noxious stimuli should not produce \\
grimacing, facial muscle movement or a motor \\
response of the limbs other than spinally mediated \\
reflexes. Any non-spinal reflex response is \\
incompatible with a brain death diagnosis.
\end{tabular}

Cautionary remarks

A multilevel assessment of motor function is important to exclude focal lesions. The clinical differentiation of spinal responses from brain-mediated motor responses requires expertise. Consultation with an experienced practitioner is recommended if the origin of a response is unclear. Alternatively, if interpretation is unclear, ancillary testing is recommended.

\section{Brain-stem reflexes}

2.1. Pupillary light reflex cranial nerves II and III

2.2. Corneal reflex - cranial nerves $\mathrm{V}$ and VII

2.3. Response to pain in the trigeminal distribution cranial nerves V and VII

2.4. Vestibulo-ocular reflex cranial nerves III, IV, VI and VIII

Vestibulo-ocular reflex cranial nerves III, IV, VI and VIII

Testing of the brain-stem reflexes comprises examination of the cranial nerves: pupils, ocular movements, facial sensation and movement, pharyngeal and tracheal response. These are tested sequentially and bilaterally when possible. All brain-stem reflexes must be absent to determine brain death.

Test: Shine a bright light into the eye and look for a pupillary constrictor response.

Interpretation: There should be no pupillary response.

Test: Touch the corneas with soft cotton wool or gauze and examine the eyes for blinking or a withdrawal response. Interpretation: No blinking or withdrawal response.

Test: Apply pain over the trigeminal distribution with deep pressure over the supra-orbital nerve bilaterally and to the condyles at the level of the temporomandibular joints.

Interpretation: No grimacing, facial muscle movemen or motor response of the limbs other than spinally mediated reflexes.

Test (cold caloric): Inspect the external auditory canal with an otoscope to confirm that the eardrum is visible. If the eardrum is not visible, the canal must be cleared before testing can occur. Elevate the head to $30^{\circ}$ to align the semi-circular canal and generate a maximal response. Flush $50 \mathrm{~mL}$ of ice-cold water into the ear canal using a syringe. Hold eyelids open and observe for eye movement for a minimum of 60 seconds.

Interpretation: No eye movement in response to the cold water; the eyes remain in the midline within the socket.

Not required/recommended: Testing for the oculocephalic (head turning/doll's eye) reflex examines the same reflex pathways as cold caloric testing but is a submaximal stimulus and is not recommended. It may also aggravate a pre-existing cervical spinal injury.
The pupils should not be pinpoint. Pupils do not have to be fully dilated. Anticholinergic drugs such as atropine can cause pupillary dilatation. Cataract or iris surgery is not a contraindication to clinical testing. Touching the sclera is not sufficient. Remove contact lenses. Examine the cornea gently as it is easily damaged.

In patients with spinal cord injuries, peripheral sensation and motor function can be lost and it is essential to adequately assess response to stimuli through brainstem-mediated sensation and motor response.

Presence of a ruptured eardrum does not invalidate the test. Fractures to base of skull or petrous temporal bone may obliterate the response on the side of the fracture. Testing should not proceed on that side if there is cerebrospinal fluid (CSF), blood or brain tissue in the external auditory canal. 
Table 2. (continued) Clinical testing for brain death - coma, brain stem reflexes, apnoea test

Clinical testing for
IX and X
2.6. Cough reflex - cranial
nerve X

\section{Apnoea test} Test and interpretation Cautionary remarks

Test: Stimulate the posterior pharyngeal wall, on both sides, with a tongue depressor or Yankauer suction. Interpretation: No gag response seen.

Test: Stimulate the tracheobronchial wall with a soft suction catheter.

Interpretation: No cough response seen.
The efferent limbs for this reflex are the phrenic nerve and the innervation of the thoracic and abdominal musculature. Therefore, it cannot be assessed in patients with a complete high cervical injury. ${ }^{[21]}$

Only proceed with the apnoea test if all above reflexes are absent. Apnoeic oxygenation is used to demonstrate lack of ventilatory drive. This involves the supply of $100 \%$ oxygen to the trachea, without providing ventilatory assistance. Through mass-movement, oxygen reaches the alveoli, allowing for transfer to the blood. In the absence of ventilation, $\mathrm{p}_{\mathrm{a}} \mathrm{CO}_{2}$ rises and stimulates the brain-stem respiratory centres, causing spontaneous breathing. As the $\mathrm{p}_{\mathrm{a}} \mathrm{CO}_{2}$ rises, the ventilatory centre is maximally stimulated by a $\mathrm{p}_{\mathrm{a}} \mathrm{CO}_{2}>60 \mathrm{mmHg}(8 \mathrm{kPa})$ and $\mathrm{pH}<7.30$. An attempt at breathing is defined as any respiratory muscle activity that results in abdominal or chest excursions or activity of accessory respiratory muscles.

Test: Pre-oxygenate the patient with $100 \%$ oxygen for 10 minutes to allow for elimination of nitrogen and to prevent hypoxaemia during the test. Perform a baseline blood gas measurement. Disconnect the patient from the mechanical ventilator. Supply continuous oxygen via a T-piece (preferred) or through a catheter inserted through the endotracheal tube and placed above the carina.

Observe continuously for any spontaneous breathing. At the end of the period without mechanical ventilation, apnoea must persist in the presence of an adequate stimulus to spontaneous ventilation, i.e. an arterial $\mathrm{p}_{\mathrm{a}} \mathrm{CO}_{2}>60 \mathrm{mmHg}(8 \mathrm{kPa})$ and an arterial $\mathrm{pH}<7.30$. Take an arterial blood gas to document the rise in $\mathrm{p}_{\mathrm{a}} \mathrm{CO}_{2}$ and change in $\mathrm{pH}$. At the end of the test, reconnect the patient to the mechanical ventilator.

Interpretation: No breathing effort is seen at any point. Apnoea testing should be aborted if:

- spontaneous respirations are witnessed during apnoea testing

- systolic blood pressure becomes $<100 \mathrm{mmH}$ or mean arterial pressure becomes $<60 \mathrm{mmHg}$ despite titration of inotropes/vasopressors (ageappropriate targets for paediatrics)

- there is sustained desaturation below $85 \%$

- an unstable arrhythmia occurs.

It is suggested that prior to aborting the apnoea test because of cardiorespiratory instability, an arterial blood gas (ABG) be sent for testing. If the $\mathrm{p}_{\mathrm{a}} \mathrm{CO}_{2}$ target is met, the apnoea test can be considered positive (consistent with brain death)
Throughout the procedure, monitor the patient's $\mathrm{SpO}_{2}$.

An option to minimise the time required for the $\mathrm{p}_{\mathrm{a}} \mathrm{CO}_{2}$ to rise to the desired level, is to adjust the minute ventilation to mild hypercarbia $\left(\mathrm{p}_{\mathrm{a}} \mathrm{CO}_{2} \sim 45\right.$ $\mathrm{mmHg}(6 \mathrm{kPa}))$ before disconnecting the patient from the ventilator.

If using a catheter, supply oxygen at $4-6 \mathrm{~L} / \mathrm{min}$.

The diameter of the catheter must be $<70 \%$ of the diameter of the endotracheal tube. When using the tracheal insufflation method, care should be taken to avoid high oxygen flows and wedging of the catheter insufflating oxygen as high intrapulmonary airway pressure may cause barotrauma.

The period of observation to achieve an adequate threshold of stimulus of the respiratory centre is variable. Usually $\mathrm{p}_{\mathrm{a}} \mathrm{CO}_{2}$ rises by $\sim 3 \mathrm{~mm} \mathrm{Hg}(0.4 \mathrm{kPa})$ for every minute of apnoea.

If starting from normocapnia, the $\mathrm{p}_{\mathrm{a}} \mathrm{CO}_{2}$ is likely to be $>60 \mathrm{mmHg}(8 \mathrm{kPa})$ after 10 minutes. If this is not the case at 10 minutes and the patient is stable, wait a further 5 minutes and repeat the arterial blood gas.

In patients with pre-existing hypercapnia, it is recommended to wait for a $\mathrm{p}_{\mathrm{a}} \mathrm{CO}_{2}$ rise $>20 \mathrm{mmHg}$ $(2.7 \mathrm{kPa})$ above the chronic level, with a $\mathrm{pH}<7.30$. Failure of the $\mathrm{p}_{\mathrm{a}} \mathrm{CO}_{2}$ to rise is most likely due to an inappropriately high oxygen flow rate via a tracheal catheter.

If hypoxia occurs, 1 - 2 positive pressure breaths can be given, and apnoea testing continued.

Adequate pre-oxygenation and recruitment usually avoids this problem. 
Two doctors are required to confirm the diagnosis of brain death. One of the doctors must have more than five years' experience (since qualification as a medical practitioner). Neither doctor must be involved with a transplantation team. ${ }^{[19]}$

Two doctors should perform the brain death testing together. If testing is done separately, there is no need for a delay between the tests; however, it is strongly advised that a single apnoea test should be done by the two doctors together. ${ }^{[5,20]}$

\subsubsection{Additional remarks: Apnoea testing}

We do not recommend using a spontaneous breathing mode and remaining connected to the ventilator during apnoea testing. Performing testing in such a manner typically requires turning off the ventilator's default safety features to prevent back-up apnoea ventilation. If a patient remains connected to a mechanical ventilator, auto-triggering can give a false impression that a person is breathing spontaneously. This occurs when the ventilator is set on a spontaneous breathing mode (pressure support ventilation) and either extrinsic or intrinsic factors generate sufficient change in airflow or negative pressure that exceeds the trigger threshold, leading to a mechanically delivered breath. Extrinsic causes for auto-triggering include excessive condensation in ventilator tubing, endotracheal tube leak, chest tubes, and random artefacts or noise in the ventilator circuit, while intrinsic causes include cardiogenic oscillation, especially in a hyperdynamic cardiovascular state. ${ }^{[5]}$

\subsubsection{Additional remarks: Clinical observations}

Observations compatible with a diagnosis of brain death are: $:^{[3]}$

- spinal reflexes (which can be spontaneous or elicited by stimulation $)^{[22,23]}$

- extension-pronation movements of the upper limbs

- nonspecific flexion of the lower limbs

- presence of deep tendon reflexes

- plantar responses, either flexor or extensor

- respiratory-like movements (shoulder elevation and adduction, back arching or intercostal expansion) without significant tidal volume

- undulating toe reflex (plantar flexion of great toe, followed by brief plantar flexion sequentially of second to fifth toes)

- Lazarus sign (bilateral arm flexion, shoulder adduction, hand raising to above the chest, and may include flexion of trunk, hips and knees)

- head turning

- sweating, blushing, tachycardia

- normal blood pressure without the need for pharmacological support

- absence of diabetes insipidus (DI) (preserved osmolar control mechanism).

Observations incompatible with brain death are:

- decerebrate or decorticate posturing

- true extensor or flexor motor responses to painful stimuli

- witnessed seizures.

\subsection{Ancillary testing}

The clinical exam is considered the most sophisticated way of testing neurological function in that it deliberately delivers a stimulus to provoke central processing followed by an efferent response. All ancillary tests infer the integrity of this stimulus-integration-response arc, but do not observe it directly. ${ }^{[5]}$

It is recommended that the clinical exam be completed to the fullest extent possible prior to conducting an ancillary test. ${ }^{[5]}$
Making an appropriate choice of an ancillary test depends on the clinician and the clinical circumstances. The most effective method to address a confounder must be identified using an educated appraisal of the strengths and weaknesses of those tests that are readily available. ${ }^{[5]}$

It is recommended that ancillary testing is required in the following circumstances: ${ }^{[5]}$

- inability to complete a clinical neurological determination of death, including the apnoea test

- confounding conditions which would invalidate clinical testing that cannot be resolved

- uncertainty regarding interpretation of spinal-mediated motor reflexes

- pre-existing severe neuromuscular disorder, such as amyotrophic lateral sclerosis or a pre-existing severe sensory neuropathy. ${ }^{[24,25]}$

Ancillary testing which establishes the absence of intracranial blood flow is the preferred method of testing where available. ${ }^{[5]}$

- radionuclide studies

- conventional four-vessel cerebral angiography

- transcranial Doppler.

It is suggested that electrophysiological testing with an electroencephalogram (EEG) not be utilised routinely as an ancillary test, given its low specificity. ${ }^{[5,26]}$ EEG testing may, however, be preferred where craniovascular impedance has been affected by an open skull fracture, decompressive craniectomy, or an open fontanelle/suture in infants. ${ }^{[5,27]}$

It is suggested that computed tomography angiography (CTA) and magnetic resonance angiography (MRA) which may be used in the investigation of these patients not be used in isolation to support a diagnosis of cerebro-circulatory arrest at present, pending further research into the sensitivity and specificity of these modalities..$^{[5,28-35]}$

\subsubsection{Technical aspects of ancillary testing}

\section{Radionuclide/brain scintigraphy studies}

To confirm brain death with radionuclide/scintigraphic techniques, the study must demonstrate absence of intracranial isotope. ${ }^{[5,36-38]}$

- Diffusible radiopharmaceuticals (brain-specific tracers) should be used preferentially.

- Single photon emission computed tomography (SPECT) is preferred over planar imaging.

- If SPECT is not available, perfusion scintigraphy with anterior and lateral planar imaging should be used with appropriate time intervals to demonstrate static filling of the posterior fossa.

\section{Cerebral angiography}

If used as an ancillary test to confirm brain death, four-vessel cerebral angiography must demonstrate absent filling at the points where the internal carotid and vertebral arteries enter the skull base, with demonstration of patent external carotid circulation. ${ }^{[39]}$

\section{Transcranial doppler}

Transcranial doppler testing is operator training dependent, needs specialised probes and requires that: ${ }^{[40,41]}$

- two examinations be performed $\geq 30$ minutes apart

- the examinations be performed bilaterally, anteriorly and posteriorly to include both internal carotid arteries as well as the vertebrobasilar circulation

- the exams illustrate biphasic oscillating flow and systolic spikes with reversal of flow in diastole in order to make a declaration of brain death. 
Transcranial doppler testing is not validated in paediatrics ${ }^{[42]}$ and is not widely available in SA.

\section{Electroencephalography (EEG)}

If EEG testing is used, it should be used in conjunction with somatosensory and brainstem auditory evoked potentials. ${ }^{[43]}$

EEG should be interpreted as demonstrating absence of brain activity when a 30 -minute study is isoelectric above 2 microvolts with a sensitivity of 2 microvolts $/ \mathrm{mm}$ and filter of 0.1 or 0.3 seconds and $70 \mathrm{~Hz} \cdot{ }^{[5,44]}$

\subsection{Paediatric considerations in brain death}

A cautious approach with a low threshold for serial examinations is recommended in this population group. ${ }^{[5,45]}$

Brain death cannot be diagnosed in neonates $<36$ weeks' corrected gestation. ${ }^{[3,4]}$

Clinical assessment of brain death in neonates and the paediatric population is the same as in adults, with age-appropriate haemodynamic targets, ${ }^{[46,47]}$ except that in neonates $(<4$ weeks) the sucking and rooting reflex should be absent in addition to the other brain-stem reflexes. ${ }^{[5]}$

Ancillary testing (as with adults) is not routinely required in this population group when clinical testing confirms brain death. ${ }^{[45]}$

A T-piece should be used for oxygenation during the apnoea test in paediatric patients in preference to the tracheal insufflation method, owing to the risk of barotrauma with this method. ${ }^{[5]}$

In patients with chronic hypoxaemia owing to cyanotic heart disease, apnoea testing should not be performed and instead an ancillary study be conducted to assist with the determination of brain death. ${ }^{\left[{ }^{[}\right]}$

\subsection{ECMO and brain death ${ }^{[48-50]}$}

The same fundamental principles of brain-death testing apply to patients on extracorporeal membrane oxygenation (ECMO).

The apnoea test should be performed in patients on veno-arterial (VA) or veno-venous (VV) ECMO unless unable to be completed owing to haemodynamic instability.

In VA ECMO, the flow rate may be adjusted to maintain a MAP $\geq 60 \mathrm{mmHg}$ during testing.

Preoxygenation prior to apnoea testing should be done by increasing the inspired oxygen via the mechanical ventilator to $100 \%$ and to the membrane lung of the ECMO machine to $100 \%$ for 10 minutes. The sweep gas flow should be titrated to $<1 \mathrm{~L} /$ min while maintaining oxygenation in order to allow a rise in carbon dioxide $\left(\mathrm{CO}_{2}\right)$. Apnoea must persist in the presence of an adequate stimulus to spontaneous ventilation, i.e. an arterial $\mathrm{p}_{\mathrm{a}} \mathrm{CO}_{2}>60 \mathrm{mmHg}(8 \mathrm{kPa})$ or $20 \mathrm{mmHg}$ above the patient's baseline and an arterial $\mathrm{pH}<7.30$. Serial blood gases may be required as achieving the rise in $\mathrm{CO}_{2}$ may take longer to achieve than in a person without ECMO support.

\subsection{Pregnancy and brain death ${ }^{[1-54]}$}

If a decision is made to offer somatic support to a brain-dead pregnant patient, it is recommended that a multidisciplinary team of intensivists, obstetricians, social workers, psychologists and neonatologists be involved.

The consent to continue providing somatic support to a braindead pregnant patient should be made in keeping with the HPCSA professional rules on consent. ${ }^{[55]}$ Due consideration to duration of support required, the high-risk nature of the delivery and an assessment of the home and legal circumstances needs to be conducted by a multidisciplinary team.

The fetus should be routinely monitored with at least daily heart rate checks, given that fetal health may affect decision-making.
Antenatal steroids should be administered to facilitate fetal lung maturation with preparations for delivery made between 26 and 33 weeks when fetal lung maturity is reached.

\subsection{Family accommodation in brain death}

While it is reasonable to provide accommodation for a finite period of time, assuming that the specific timeframe for doing so is brief, that resources allow, and that a family is informed of the timeframe in advance, accommodation ordinarily should not be provided for a period greater than 24 hours.

It is ethically and legally appropriate for the treating team to end somatic support for a body when the family has been adequately counselled on the diagnosis of death and the option of organ donation explored.

An additional clinician in the hospital can provide the family with a second opinion regarding determination of brain death if it is felt that this may assist the family in accepting the person's death.

Even in the setting of requests for accommodation, support should be discontinued if a person has been declared brain-dead and the hospital bed is required for a living patient where no other bed is available..$^{[5]}$

\section{Circulatory death}

\subsection{Preconditions for circulatory death testing}

To declare death on circulatory grounds, one of the following criteria must be met:

- it is inappropriate to attempt cardiopulmonary resuscitation

- attempts at cardiopulmonary resuscitation have failed

- treatment aimed at sustaining life has been withdrawn.

Treatment may be withdrawn because: ${ }^{[56]}$

- it has been assessed to be of no further benefit to the patient (nonbeneficial/futile) and is not in his or her best interest to continue

- it is in respect of the patient's wishes via an advanced directive to refuse life-sustaining treatment

- it is in respect of the patient's wishes as expressed by their legal surrogate decision-maker.

\subsection{Circulatory death testing}

The patient should be observed by the person responsible for confirming death for a minimum period of five minutes to establish that irreversible circulatory arrest has occurred. ${ }^{[57]}$

The absence of mechanical cardiac function should be confirmed using a combination of the following:

- absence of a central pulse on palpation

- absence of heart sounds on auscultation.

In the hospital setting, clinical assessment of absent mechanical cardiac function can be supplemented by one or more of the following:

- absence of pulsatile flow using direct intra-arterial pressure monitoring

- absence of contractile activity using echocardiography.

Once mechanical cardiac function is confirmed as absent by clinical assessment, intra-arterial pressure monitoring or echocardiography, the 5-minute waiting period can begin.

Any spontaneous return of circulatory or respiratory activity during the five-minute observation period should prompt a reset of the observation period from this point. ${ }^{[58]}$

Spontaneous return of circulatory or respiratory activity is not an indication to begin resuscitation efforts in a context where this has been determined to be inappropriate. 
After the 5-minute period of continued circulatory arrest has passed, the absence of pupillary responses to light and of any motor response to supra-orbital pressure should be confirmed. ${ }^{[59-61]}$ The time of death is recorded as the time at which these criteria are fulfilled. ${ }^{[1]}$

It is inappropriate to initiate any intervention that has the potential to restore cerebral perfusion after death has been confirmed. ${ }^{[3,62]}$ In cases where organ donation after circulatory death takes place, a second doctor is required to certify the death. ${ }^{[19]}$

\section{Organ donation}

End-of-life care should, as standard of care, explore the patient's wishes regarding organ and tissue donation. ${ }^{[63]}$

The recommended time for a clinical assessment of organ donation potential (with the transplant co-ordinator) is when the treating team makes a decision to perform brain-death testing or to initiate discussions with the family to withdraw life-sustaining treatment. This allows clarification of the potential for organ and tissue donation prior to end-of-life discussions, and an informed approach for consent from the family. ${ }^{[64]}$

Somatic support of a brain-dead patient is appropriate to allow the possibility of organ and tissue donation to be fully explored with the family. ${ }^{[3]}$

\section{Training and documentation}

All doctors should be trained in the determination of death. It is recommended that a standardised checklist be used for death determination and its documentation. ${ }^{[65,66]}$

Consultation with a medical practitioner experienced in the diagnosis of brain-death is advised in situations where the diagnosis and testing are uncertain.

All doctors training in disciplines that manage patients with severe brain injuries should receive detailed training in the preconditions for brain-death testing, clinical testing procedures, indications for and utility of ancillary testing, somatic support of the brain-dead patient, and techniques for effective counselling of families. ${ }^{[5,65,67]}$

All phases of the brain death determination should be documented in the medical record, including: $:^{[5,68]}$

- aetiology of the coma

- absence of confounders

- full details of the clinical testing performed, including apnoea testing and laboratory values

- neuroimaging results if done

- the reason for ancillary testing if performed and the findings

- time and date of death

- identity of the practitioners performing the evaluation, with their HPCSA numbers.

In cases where brain death can be determined with a neurological exam and ancillary testing is not needed, the time of death must be documented as the time the arterial $\mathrm{p}_{\mathrm{a}} \mathrm{CO}_{2}$ reaches the target, with no spontaneous respirations seen, during the apnoea test confirmed by two doctors. ${ }^{[3,5]}$

In cases where the doctors were not able to complete the apnoea test together, the time of death will be upon completion of the second apnoea test. ${ }^{[3,5]}$

In cases where ancillary testing is performed, the time of death must be documented as the time that the ancillary test results are formally interpreted and documented. ${ }^{[3,5]}$

Determination of death on the basis of circulatory criteria should be documented in the medical record, including:

- in cases where resuscitation was attempted, a record of the resuscitation attempts and the time resuscitation was stopped
- in cases where resuscitation was not attempted, the rationale

- confirmation of absent pupillary and pain response, respiratory effort and circulation after a 5-minute period

- time and date of death

- identity of the practitioner/s performing the evaluation, with their HPCSA number/s.

\section{Strengths and limitations}

This guidance document offers clear, pragmatic evidence-based medical guidance in the determination of death in the SA context. The provided checklists (Figs 1 - 4) offer a summary of the recommendations for clinical application. A limitation of this document is that a lack of high-quality data from large randomised clinical trials prevented the use of formal analytical techniques (GRADE, AGREE) in the literature appraisal. It is also acknowledged that these recommendations were developed without direct patient, cultural and religious input; however, the panel of experts did represent a broad range of cultural and religious viewpoints from across SA.

\subsection{Applicability, barriers, facilitators and cost implications of these guidelines}

Barriers to effective implementation of death determination guidelines include a lack of uptake and acceptance by both clinicians and the public as well as the challenge of ensuring cultural and religious engagement and support for the medical determination of death. The endorsement and application of these guidelines is to be formally encouraged across all healthcare disciplines. Undergraduate and postgraduate teaching should consider these guidelines as the standard of care for the determination of death in $\mathrm{SA}$ and incorporate them into their training programmes. Hospital policies and standard operating procedures should similarly align themselves with the guidelines to prevent differing practices across institutions, which can cause confusion among clinicians, families and the general public. ${ }^{[9,69]}$ Use of the provided checklists is expressly recommended in the guidelines to facilitate clinicians to apply them in their daily practice. Continuing professional development programmes should incorporate these guidelines in the education of practising clinicians.

Pursuing a diagnosis of brain death may entail additional resources, and the clinician must judge the appropriateness in each clinical context. The beneficial effects of organ and tissue donation to the SA public and healthcare system are large. Exploring the option of organ and tissue donation at the end of life is a standard of care that should be fully assessed and appropriately explored with all patients and their families. Folder reviews and audits of documentation completed at end of life to assess compliance with these guidelines will assist in improving standards in death determination and end-of-life care. ${ }^{[70]}$

\section{Conclusion}

Death can be determined with complete certainty by medical professionals adhering to these guidelines which offer the clinician the latest evidence in best practice for determining death by either neurological or circulatory criteria. Use of the attached checklists is recommended.

Acknowledgements. The Critical Care Society of Southern Africa for facilitating the creation of these guidelines.

Author contributions. DT led the consensus process, developed and supervised the methodology, and chaired the face-to-face round-table meeting; was responsible for initial literature search, drafting of consensus 
key questions and supervised the Delphi process, including the drafting and grading of recommendations; drafted the manuscript, supervised revisions to the drafts, and approved the final manuscript.

IJ, DG, FP, KDV chose the participants, developed and supervised the methodology, participated in the Delphi process and face-to-face roundtable meeting, performed literature searches, participated in manuscript drafting and revisions to the drafts, and approved the final manuscript. SM, RM, MM, BM, DB, BR, NM, GAR, NW, BL, MS, NA participated in the Delphi process and face-to-face round-table meeting, drafted and graded associated recommendations; participated in revisions to the drafts and approved the final manuscript.

IC participated in the Delphi process, drafted and graded associated recommendations; participated in revisions to the drafts and approved the final manuscript.

Funding. These guidelines were internally funded by the Critical Care Society of Southern Africa (CCSSA), a registered non-profit organisation dedicated to delivering appropriate, quality care to the critically ill. The authors declare that the views or interests of the CCSSA have not influenced the final recommendations.

Conflicts of interest. All authors declare that there were no potential conflicts of interest.

1. World Health Organization. Clinical criteria for the determination of death, WHO technical expert consultation, WHO Headquarters, Geneva, Switzerland, 22 - 23 September 2014. Geneva: WHO; 2017. https://apps.who.int/iris/bitstream/handle/10665/254737/WHO-HIS-SDS-2017.5-eng.pdf;jsessionid=D BBFDE5645ED697AEA0D373772F54BDF? sequence=1 (accessed 4 August 2020).

2. Wijdicks EF, Varelas PN, Gronseth GS, Greer DM. Evidence-based guideline update: Determining brain . Wijdicks EF, Varelas PN, Gronseth GS, Greer DM. Evidence-based guideline update: Determining brain
death in adults. Report of the Quality Standards Subcommittee of the American Academy of Neurology. death in adults. Report of the Quality Standards Subcommittee of the American Acade
Neurology 2010;74(23):1911-1918. https://doi.org/10.1212\%2Fwnl.0b013e3181e242a8

Neurology 2010;74(23):1911-1918. https://doi.org/10.1212\%2Fwnl.0b013e3181e242a 8
3. Australian Society NZIC. The ANZICS statement on death and organ donation: Australian and New 3. Australian Society NZIC. The ANZICS statement on death and organ donation: Australian and New
Zealand Intensive Care Society, 2008. https://csds.qld.edu.au/sdc/Provectus/ELI/Module\%202\%20-\%20 Zealand Intensive Care Society, 2008. https://csds.qld.edu.au/sdc/Provectus/ELL/Module\%202\%20-\%20
Organ\%20donation\%20after\%20brain\%20death/files/ANZICS\%20Statement\%20on\%20\%20Death $\% 20$ and\%20Organ\%20Donation\%20Edition\%203.2\%20(3).pdf (accessed 4 August 2020).

4. Shemie SD, Doig C, Dickens B, et al. Severe brain injury to neurological determination of death: Canadian forum recommendations. Canadian Med Ass J 2006;174(6):S1-13. https://doi. org $/ 10.1503 \% 2 \mathrm{Fcmaj} .045142$

5. Greer DM, Shemie SD, Lewis A, et al. Determination of brain death/death by neurologic criteria: The World Brain Death Project. JAMA 2020;324(11):1078-1097. https://doi:10.1001/jama.2020.11586

6. Wahlster S, Wijdicks EF, Patel PV, et al. Brain death declaration: Practices and perceptions worldwide. Neurology 2015;84(18):1870-1879. https://doi.org/10.1212\%2Fwnl.0000000000001540

7. Chang MY, McBride LA, Ferguson MA. Variability in brain death declaration practices in pediatric head trauma patients. Pedia Neuro 2003;39(1):7-9. https://doi.org/10.1159\%2F000070871

8. Citerio G, Crippa IA, Bronco A, Vargiolu A, Smith M. Variability in brain death determination in Europe: Citerio G, Crippa IA, Bronco A, Vargiolu A, Smith M. Variability in brain death determination in Europe:
Looking for a solution. Neurocrit Care 2014;21(3):376-382. https://doi.org/10.1007\%2Fs12028-014-9983-x

Looking for a solution. Neurocrit Care 2014;21(3):376-382. https://doi.org/10.1007\%2Fs12028-014-9983-X
9. Greer DM, Varelas PN, Haque S, Wijdicks EF. Variability of brain death determination guidelines in 9. Greer DM, Varelas PN, Haque S, Wijdicks EF. Variability of brain death determination guidelines in
leading US neurologic institutions. Neurology 2008;70(4):284-289. https://doi.org/10.1212\%2F01. wnl.0000296278.59487.c2

10. Wijdicks EFM. Brain death worldwide: Accepted fact but no global consensus in diagnostic criteria. Neurology 2002;58(1):20-25. https://doi.org/10.1212\%2Fwnl.58.1.20

11. Brouwers MC, Kerkvliet K, Spithoff K, Consortium ANS. The AGREE Reporting Checklist: A tool to improve reporting of clinical practice guidelines. BMJ 2016;352:11152. https://doi.org/10.1136\%2Fbmj.i1152

12. Dalkey N, Helmer O. An experimental application of the Delphi method to the use of experts. Manag Sci 1963;9(3):458-467. https://doi.org/10.1287\%2Fmnsc.9.3.458

13. Brouwers MC, Kho ME, Browman GP, et al. AGREE II: Advancing guideline development, reporting and evaluation in health care. Canadian Med Ass J 2010;182(18):E839-E842. https://doi. org $/ 10.1503 \% 2 \mathrm{Fcmaj} .090449$

14. Akins RB, Tolson H,Cole BR. Stability of responsecharacteristics of a Delphi panel: Application of bootstrap data expansion. BMC Med Res Method 2005;5(1):37. https://doi.org/10.1186\%2F1471-2288-5-37

15. Williamson PR, Altman DG, Bagley H, et al. The COMET handbook: Version 1.0. Trials 2017;18(3):280. https://doi.org/10.1186\%2Fs13063-017-1978-4

16. Gardiner D, Shemie S, Manara A, Opdam H. International perspective on the diagnosis of death. Br J Anaesthesia 2012;108 Suppl 1:i14-28. https://doi.org/10.1093/bja/aer397

17. Academy of Medical Royal Colleges. A code of practice for the diagnosis and confirmation of brain death. London: AOMRC,2008.

18. Busl KM, Greer DM. Pitfalls in the diagnosis of brain death. Neurocrit Care 2009;11(2):276-287. https:// doi.org/10.1007\%2Fs12028-009-9231-y

19. McQuoid-Mason D. Medicine and the law. Human tissue and organ transplant provisions: Chapter 8 of the National Health Act and its Regulations, in effect from March 2012 - what doctors must know. S Afr Med J 2012;102(9):730-732. https://doi.org/10.7196\%2Fsamj.6047

20. Varelas PN, Rehman M, Abdelhak T, et al. Single brain death examination is equivalent to dual brain death examinations. Neurocrit Care 2011;15(3):547-553. https://doi.org/10.1007\%2Fs12028-011-9561-4

21. Waters C, French G, Burt M. Difficulty in brainstem death testing in the presence of high spinal cord injury. Br J Anaesthesia 2004;92(5):760-764. https://doi.org/10.1093\%2Fbja\%2Faeh117

22. Saposnik G, Basile VS, Young GB. Movements in brain death: A systematic review. Can J Neurol Sci [Le journal canadien des sciences neurologiques] 2009;36(2):154-160. https://doi. Neurol Sci [Le journal canadien
org $/ 10.1017 \% 2 \mathrm{~F} 5031716710000651 \mathrm{x}$

23. Kumar A, Tummala P, Feen ES, Dhar R. Spinal decerebrate-like posturing after brain death: A case report and review of the literature. J Intensive Care Med 2016;31(9):622-624. https://doi. org $/ 10.1177 \% 2 \mathrm{~F} 0885066616646076$
24. Ravikumar S, Poysophon P, Poblete R, Kim-Tenser M. A case of acute motor axonal neuropathy mimicking brain death and review of the literature. Front Neurol 2016;7:63. https://doi mimicking brain death and
org $10.3389 \% 2$ ffneur.2016.00063

25. Ragazzoni A, Grippo A, Tozzi F, Zaccara G. Event-related potentials in patients with total locked-in state due to fulminant Guillain-Barré syndrome. Int J Psychophysiol 2000;37(1):99-109. https://doi.org/10.10 $16 \% 2 \mathrm{Fs} 0167-8760 \% 2800 \% 2900098-2$

26. Paolin A, Manuali A, Di Paola F, et al. Reliability in diagnosis of brain death. Int Care Med 1995;21(8):657662. https://doi.org/10.1007\%2Fbf01711544

27. Okuyaz C, Gucuyener K, Karabacak NI, Aydin K, Serdaroglu A, Cingi E. Tc-99m-HMPAO SPECT in the diagnosis of brain death in children. J Japan Pedia Soc 2004;46(6):711-714. https://doi. org/10.1111\%2Fj.1442-200x.2004.01976.x

28. Karantanas AH, Hadjigeorgiou GM, Paterakis K, Sfiras D, Komnos A. Contribution of MRI and MR angiography in early diagnosis of brain death. Eur Rad 2002;12(11):2710-2716. https://doi. org/10.1007\%2Fs00330-002-1336-Z

29. Sohn C-H, Lee H-P, Park JB, et al. Imaging findings of brain death on 3-tesla MRI. Korean J Rad 2012;13(5):541-549. https://doi.org/10.3348\%2Fkir.2012.13.5.541

30. Ishii K, Onuma T, Kinoshita T, Shiina G, Kameyama M, Shimosegawa Y. Brain death: MR and MR . Ishii K, Onuma T, Kinoshita T, Shiina G, Kameyama M,
angiography. Am J Neuroradiology 1996;17(4):731-735.

31. Sawicki M, Sołek-Pastuszka J, Chamier-Ciemińska K, Walecka A, Walecki J, Bohatyrewicz R. Computed Sawicki M, Sołek-Pastuszka J, Chamier-Ciemińska K, Walecka A, Walecki J, Bohatyrewicz R. Computed
tomography perfusion is a useful adjunct to computed tomography angiography in the diagnosis of brain tomography perfusion is a useful adjunct to computed tomography angiography in the diagnosis of
death. Clin Neuroradiology 2019;29(1):101-108. https://doi.org/10.1007\%2Fs00062-017-0631-7

32. Frampas E, Videcoq M, De Kerviler E, et al. CT angiography for brain death diagnosis. Am Neuroradiology 2009;30(8):1566-1570. https://doi.org/10.3174\%2Fajnr.a1614

33. Garrett MP, Williamson RW, Bohl MA, Bird CR, Theodore N. Computed tomography angiography as a confirmatory test for the diagnosis of brain death. J Neurosurgery 2018;128(2):639-644. https://doi org/10.3171\%2F2016.10.jns161042

34. Shankar J, Vandorpe R. CT perfusion for confirmation of brain death. Am J Neuroradiology 2013;34(6):1175-1179. https://doi.org/10.3174\%2Fajnr.a3376

35. Taylor T, Dineen RA, Gardiner DC, Buss CH, Howatson A, Pace NL. Computed tomography (CT) angiography for confirmation of the clinical diagnosis of brain death. Cochrane Database Syst Rev 2014(3): CD009694. https://doi.org/10.1002\%2F14651858.cd009694.pub2

36. Joffe AR, Lequier L, Cave D. Specificity of radionuclide brain blood flow testing in brain death: Case report and review. J Int Care Med 2010;25(1):53-64. https://doi.org/10.1177\%2F0885066609355388

37. Flowers JW, Patel BR. Radionuclide angiography as a confirmatory test for brain death: a review of 229 studies in 219 patients. South Med J 1997;90(11):1091-1096. https://doi.org/10.1097\% 2F00007611-199711000-00007

38. Donohoe KJ, Agrawal G, Frey KA, et al. SNM practice guideline for brain death scintigraphy 2.0. J Nucl Med Technol 2012;40(3):198-203. https://doi.org/10.2967\%2Fjnmt.112.105130

39. Braun M, Ducrocq X, Huot J-C, Audibert G, Anxionnat R, Picard L. Intravenous angiography in brain death: Report of 140 patients. Neuroradiology 1997;39(6):400-405. https://doi. org $/ 10.1007 \% 2 \mathrm{Fs} 002340050432$

40. Chang JJ, Tsivgoulis G, Katsanos AH, Malkoff MD, Alexandrov AV. Diagnostic accuracy of transcranial doppler for brain death confirmation: Systematic review and meta-analysis. Am J Neuroradiology 2016;37(3):408-414. https://doi.org/10.3174\%2Fajnr.a4548

41. Monteiro LM, Bollen CW, van Huffelen AC, Ackerstaff RG, Jansen NJ, van Vught AJ. Transcranial Doppler ultrasonography to confirm brain death: A meta-analysis. Int Care Med 2006;32(12):1937-1944. https://doi.org/10.1007\%2Fs00134-006-0353-9

42. Mata-Zubillaga D, Oulego-Erroz I. Persistent cerebral blood flow by transcranial Doppler ultrasonography in an asphyxiated newborn meeting brain death diagnosis: Case report and review of the literature. J Perinatol 2012;32(6):473-475. https://doi.org/10.1038\%2Fjp.2011.147

43. Guérit J-M, Amantini A, Amodio P, et al. Consensus on the use of neurophysiological tests in the intensive care unit (ICU): Electroencephalogram (EEG), evoked potentials (EP), and electroneuromyography (ENMG). Neurophysiologie Clinique/Clinical Neurophysiology 2009;39(2):71-83. https://do org/10.1016\%2Fj.neucli.2009.03.002

4. Wijdicks EF. Determining brain death in adults. Neurology 1995;45(5):1003-1011. https://doi org/10.1212\%2Fwnl.45.5.1003

45. Abbott J, Kennedy C, Marshment V, Mcfadzean J, Mcintosh N, Snowdon C. Royal College of Pediatrics and Child Health. The diagnosis of death by neurological criteria in infants less than 2 month old. 2015. https://nhsbtdbe.blob.core.windows.net/umbraco-assets-corp/1354/neurological-death-dnc-guide-final. pdf. London, UK: Royal College of Paediatrics and Child Heath, 2015.

46. Samuels M, Wieteska S, eds. Advanced Paediatric Life Support: A Practical Approach to Emergencies. 6th 6. Samuels M, Wieteska S, eds. Advanced Paediatric Life Support: A Practical Approach to Emergencies. 6th
ed. USA: John Wiley \& Sons, 2016:7. https://onlinelibrary.wiley.com/doi/book/10.1002/9781119241225 47. International Guidelines 2000 for Cardiopulmonary Resuscitation (CPR) and Emergency Cardiovascular International Guidelines 2000 for Cardiopulmonary Resuscitation (CPR) and Emergency Cardiovascular
Care (ECC); Part 10: Pediatric Advanced Life Support. Circulation 2000; 102(Suppl 1):291-342. https:// www.ahajournals.org/doi/epub/10.1161/circ.102.suppl_1.I-291

8. Shah V, Lazaridis C. Apnea testing on extracorporeal membrane oxygenation: Case report and literature review. J Crit Care 2015;30(4):784-786. https://doi.org/10.1016\%2Fj.jprc.2015.03.028

49. Smilevitch P, Lonjaret L, Fourcade O, Geeraerts T. Apnea test for brain death determination in patient on extracorporeal membrane oxygenation. Neuro Care 2013;19(2):215-217. https://doi. org/10.1007\%2Fs12028-013-9845-y

50. Migliaccio M, Zagli G, Cianchi G, et al. Extracorporeal membrane oxygenation in brain-death organ and tissues donors: A single-centre experience. Br J Anaesthesia 2013;111(4):673-674. https://doi. org $/ 10.1093 \% 2 \mathrm{Fbja} \% 2 \mathrm{Faet} 323$

51. Powner DJ, Bernstein IM. Extended somatic support for pregnant women after brain death. Crit Care Med 2003;31(4):1241-1249. https://doi.org/10.1097\%2F01.ccm.0000059643.45027.96

52. Farragher R, Marsh B, Laffey JG. Maternal brain death - an Irish perspective. Irish J Med Sci 2005;174(4):55-59. https://doi.org/ $/ 10.1007 \% 2 \mathrm{Fbf0316898}$

53. Esmaeilzadeh M, Dictus C, Kayvanpour E, et al. One life ends, another begins: Management of a brain-dead pregnant mother - a systematic review. BMC Med 2010;8:74. https://doi. org/10.1186\%2F1741-7015-8-74

54. McQuoid-Mason D. Terminating the pregnancy of a brain-dead mother: Does a fetus have a right to life? The law in South Africa. S Afr J Bioethics Law 2014;7(2):44-46. https://doi.org/10.7196\%2Fsajbl.317

55. Health Professionals Council of South Africa. Seeking patients' informed consent: The ethical considerations. HPCSA; September 2016. https://www.hpcsa.co.za/Uploads/Professional_Practice/Conduct $\% 20 \% 26 \% 20$ Ethics/Booklet $\% 204 \% 20$ Informed $\% 20$ Consent $\% 20$ September\%20\%202016.pdf.

56. Health Professions Council of South Africa. Guidelines for Withholding and Withdrawing Treatment 2016. https://www.hpcsa.co.za/Uploads/Professional_Practice/Conduct $\% 20 \% 26 \% 20$ Ethics/Booklet\%207\%20Guidelines\%20withholding\%20and\%20withdrawing\%20treatment $\% 20$ September\%202016.pdf.

57. Committee E, Medicine SoCC. Recommendations for nonheartbeating organ donation. A position paper by the Ethics Committee, American College of Critical Care Medicine, Society of Critical Care Medicine. Crit Care Med 2001;29(9):1826. https://doi.org/10.1097\%2F00003246-200109000-00029

58. Sheth KN, Nutter T, Stein DM, Scalea TM, Bernat JL. Autoresuscitation after asystole in patients being considered for organ donation. Crit Care Med 2012;40(1):158-161. https://doi.org/10.1097\%2Fccm.0 b013e31822fob2a 
59. Hornby K, Hornby L, Shemie SD. A systematic review of autoresuscitation after cardiac arrest. Crit Care Med 2010;38(5):1246-1253. https://doi.org/10.1097\%2Fccm.0b013e3181d8caaa

60. Clute HL, Levy WJ. Electroencephalographic changes during brief cardiac arrest in humans Anesthesiology 1990;73(5):821-825. https://doi.org/10.1097\%2F00000542-199011000-00004

61. Losasso TJ, Muzzi DA, Meyer FB, Sharbrough FW. Electroencephalographic monitoring of cerebral function during asystole and successful cardiopulmonary resuscitation. Anesth Anal 1992;75(6):1021function during asystole and successful cardiopulmonary resus

62. Gardiner D, Shemie S, Manara A, Opdam H. International perspective on the diagnosis of death. Br Anaest 2012;108(SUPPL 1):i14-i28. https://doi.org/10.1093\%2Fbja\%2Faer397

63. Domínguez-Gil B, Murphy P, Procaccio F. Ten changes that could improve organ donation in the intensive care unit. Intensive Care Med 2016;42(2):264-267. https://doi.org/10.1007\%2Fs00134 015-3833-y

64. Chamberlain K, Baker M, Kandaswamy P, Shaw E, McVeigh G, Siddiqui F. Donor identification and consent for deceased organ donation: Summary of NICE guidance. BMJ 2012;344:e341. https://do org $/ 10.1136 \% 2 \mathrm{Fbmj} . \mathrm{e} 341$

65. Shappell CN, Frank JI, Husari K, Sanchez M, Goldenberg F, Ardelt A. Practice variability in brain death determination: A call to action. Neurology 2013;81(23):2009-2014. https://doi.org/10.1212\%2F01. wnl.0000436938.70528.4a
66. Wang MY, Wallace P, Gruen JP. Brain death documentation: Analysis and issues. Neurosurgery 2002;51(3):731-735. https://doi.org/10.1097\%2F00006123-200209000-00021

67. Kashkoush A, Weisgerber A, Dharaneeswaran K, Agarwal N, Shutter L. Medical training and the brain . Kashkoush A, Weisgerber A, Dharaneeswaran K, Agarwal N, Shutter L. Medical training and the brain
death exam: A single institution's experience. World Neuro 2017;108:374-378. https://doi.org/10.1016/j. death exam: A sing ir

68. Wijdicks EFM, Varelas PN, Gronseth GS, Greer DM. Evidence-based guideline update: Determining brain death in adults: Report of the quality standards subcommittee of the American Academy of Neurology. Neurology 2010;74(23):1911-1918. https://doi.org/10.1212\%2Fwnl.0b013e3181e242a8

6. Citerio G, Crippa IA, Bronco A, Vargiolu A, Smith M. Variability in brain death determination in Europe: Looking for a solution. Neuro Care 2014;21(3):376-382. https://doi.org/10.1007\%2Fs12028-014-9983-x 0. Wijdicks EFM. Critical synopsis and key questions in brain death determination. Int Care Med 2019;45(3):306-309. https://doi.org/10.1007\%2Fs00134-019-05549-6

Accepted 17 November 2020 


\section{BRAIN DEATH CERTIFICATION}

Summary Recommendations - South African Death Determination Guidelines Checklist

Name:

Hospital Number:

Date of Birth:

Doctor 1

Examination ${ }^{\star \star}$

\section{Doctor 1}

Name:

HPCSA Number:

Signature:

Date and time:

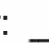

-

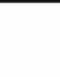




\section{BRAIN DEATH CLINICAL TESTING}

Summary Recommendations - South African Death Determination Guidelines Checklist

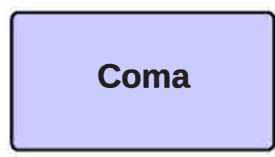

\section{Pupillary light} reflex

\section{Corneal reflex}

Response to pain in the trigeminal distribution

Gag reflex

Cough reflex

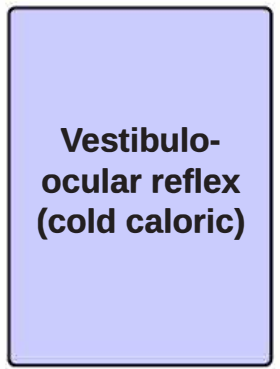

Apnoea test
Apply deep pressure to: the temporomandibular joints, the supra-orbital notch bilaterally, the sternal notch and all four extremities via deep nail bed pressure. There should be no true motor response.

Shine a bright light into the eye and look for a pupillary constrictor response. There should be no pupillary response.

Touch the corneas with soft cotton wool or gauze and examine the eyes for blinking or a withdrawal response.

There should be no blinking or withdrawal response.

Apply pain over the trigeminal distribution, e.g. pressure over the supra-orbital nerve and to the condyles at the level of the temporomandibular joints.

There should be no facial or limb movement.

Stimulate the posterior pharyngeal wall, on both sides, with a tongue depressor or Yankauer suction.

There should be no gag response.

Stimulate the tracheobronchial wall with a soft suction catheter.

There should be no cough response.

Inspect the external auditory canal with an otoscope to confirm that the eardrum is visible. If the eardrum is not visible, the canal must be cleared before testing. Elevate the head to $30^{\circ}$ to align the semi-circular canal and generate a maximal response. Flush $50 \mathrm{~mL}$ of ice-cold water into the ear canal using a syringe. Hold eyelids open and observe for eye movement for a minimum of 60 seconds.

There should be no eye movement in response to the cold water; the eyes remain in the midline within the socket.

Observations that are incompatible with a diagnosis of brain death:

\section{Observations that are compatible with a diagnosis of brain death:}

Spinal reflexes, sweating, blushing, tachycardia, and a normal blood pressure.

Fig. 2. Summary recommendations - Brain death clinical testing (https://criticalcare.org.za/resource/death-determination-checklists/). 


\section{APNOEA TESTING}

Summary Recommendations - South African Death Determination Checklist

\section{Background:}

Only proceed with the apnoea test to confirm brain death if all other brainstem reflexes are absent and patient is haemodynamically stable (may be on inotropes).

Two doctors should perform a single apnoea test together.

\section{Testing procedure:}

Pre-oxygenate the patient with 100 percent oxygen for 10 minutes to prevent hypoxaemia during the test.

Perform a baseline ABG.

Assess baseline $\mathrm{CO}_{2}$ level $\left(\mathrm{p}_{\mathrm{a}} \mathrm{CO}_{2} 35\right.$ - 45 $\mathrm{mmHg}, 4.6$ - $6.0 \mathrm{kPa})$.

Disconnect the patient from the mechanical ventilator and supply continuous oxygen via a

T-piece (preferred) or through a catheter inserted through the endotracheal tube and placed above the carina.*

Observe continuously for any spontaneous breathing.

\section{Halt testing if:}

- Spontaneous respirations are witnessed; - Systolic blood pressure $<100 \mathrm{~mm} \mathrm{Hg}$ or mean arterial pressure $<60 \mathrm{~mm} \mathrm{Hg}$ despite titration of inotropes/vasopressors;

- Sustained oxygen desaturation <85\%; - An unstable arrhythmia occurs.

It is suggested that prior to aborting the apnoea test due to cardiorespiratory instability, an arterial blood gas (ABG) be sent for testing. If the $\mathrm{p}_{\mathrm{a}} \mathrm{CO}_{2}$ target is met, the apnoea test can be considered positive (consistent with brain death).

\section{Interpretation:}

In cases of brain death, apnoea must be demonstrated in the presence of an adequate stimulus to spontaneous ventilation, i.e. an arterial $\mathrm{p}_{\mathrm{a}} \mathrm{CO}_{2}>60 \mathrm{mmHg}(8 \mathrm{kPa})$ and an arterial $\mathrm{pH}<7.30$.

In patients with pre-existing hypercapnia, it is recommended to wait for $\mathrm{a}_{\mathrm{a}} \mathrm{CO}_{2}$ rise of $>20$ $\mathrm{mmHg}(2.7 \mathrm{kPa})$ above the chronic level, with a $\mathrm{pH}<7.30$.

Attempt at breathing is defined as any respiratory muscle activity that results in abdominal or chest excursions or activity of accessory respiratory muscles.

Duration (Target $\mathrm{p}_{\mathrm{a}} \mathrm{CO}_{2}$ )

The period of observation to achieve an adequate threshold of stimulus of the respiratory centre is variable.

Usually $\mathrm{p}_{\mathrm{a}} \mathrm{CO}_{2}$ rises by $-3 \mathrm{mmHg}(0.4 \mathrm{kPa})$ for every minute of apnoea.

If starting from normocapnia, the $\mathrm{p}_{\mathrm{a}} \mathrm{CO}_{2}$ is likely to be $>60 \mathrm{mmHg}(8 \mathrm{kPa})$ after 10 minutes.

If this is not the case at 10 minutes and the patient is stable, wait a further 5 minutes and repeat the arterial blood gas.

An option to minimise the time required for the $\mathrm{p}_{\mathrm{a}} \mathrm{CO}_{2}$ to rise to the desired level, is to adjust the minute ventilation to mild hypercarbia $\left(\mathrm{p}_{\mathrm{a}} \mathrm{CO}_{2} \sim 45 \mathrm{mmHg}[6 \mathrm{kPa}]\right.$ ) beforehand.

If unable to complete testing, consider:

If hypoxia occurs 1-2 positive pressure breaths can be given, and apnoea testing continued.

Adequate pre-oxygenation and recruitment usually avoids this problem. 


\section{CIRCULATORY DEATH CERTIFICATION}

Summary Recommendations - South African Death Determination Guidelines Checklist

Name:

Hospital Number:

Date of Birth:

\section{Prerequisites}

Inappropriate to attempt cardiopulmonary resuscitation or attempts at cardiopulmonary resuscitation have failed

Intensive support (ventilation, inotropes) withdrawn at (time) on

$$
\text { I }
$$$$
\text { I }
$$

(date)

\section{Examination}

Absence of mechanical cardiac function confirmed by one of the following:

- Absence of central pulse / heart sounds on auscultation

- Absence of pulsatile flow on intra-arterial BP monitoring

- Absence of contractile activity on echocardiography

Patient observed for 5 minutes with no respiratory or circulatory activity seen*

At end of 5 minutes observation period, lack of pupillary response to light and motor response to supraorbital pain confirmed

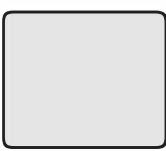

Death certified at (time) on

1

(date) by

\section{Doctor 1}

Name:

HPCSA Number:

Signature:

Doctor 2 (in case of organ donation**)

Name:

HPCSA Number:

Signature:

*Any spontaneous return of circulatory or respiratory activity during the 5-minute observcation period requires a reset of the observation period from this point

** In cases of possible organ donation after circulatory death one doctor with more than 5 years experience, neither doctor may be involved with the transplant team.

Fig. 4. Summary recommendation - Circulatory death certification checklist (https://criticalcare.org.za/resource/death-determination-checklists/). 